\title{
Entre el XVI centenario de la conversión de S. Agustín (1986) y el de su de bautismo (1987)
}

Todavía hay que escanciar vino, buen vino, desde el reciente Congreso Internacional Agustiniano de Roma, del 15 al 20 de septiembre. Todavía quedan esencias puras en ese frasco que allíse ha abierto y ofrecido para el mundo actual, particularmente para bien de la juventud de nuestro tiempo, de todo tiempo. Veamos algunas perspectivas, frutos y esperanzas de futuro.

\section{Bienaventuranzas y conversión}

De las 155 comunicaciones y relaciones, el de las bienaventuranzas ha sido el que más tiempo ha ocupado entre los 300 profesores de todo el mundo, el que más interés ha despertado, sobre todo la bienaventuranza de la paz, no sólo la de ser pacífico («pacific») sino también «peacemaker», hacedor de la paz. Por ahí comenzó precisamente san Agustín sus estudios y comentarios a los Evangelios.

Pero este tema tan sugestivo, entonces y ahora, ha estado enmarcado en el motivo específico que nos convocaba y reunía: el de la conversión y el bautismo: hoy podía enunciarse de esta otra manera: la conversión al bautismo recibido (de niños); «convertíos y bautizaos» (el de los adultos como san Agustín); tomar en serio la pastoral del bautismo (todos). Ésas fueron las tres conclusiones a las que llegaba la Relación que expuse sobre «el bautismo como fundamento de la espiritualidad matrimonial y familiar según S. Agustín».

Y en la actualidad, es el problema más agudo que tiene hoy la Iglesia: el de los bautizados no creyentes, la necesidad de la segunda evangelización (más difícil que la primera) y tomar en serio la iniciación cristiana.

Se hicieron análisis profundos y acertados sobre la conversión, y sus verbos constitutivos (dichos y explicados en todos los idiomas): amar, buscar, convertirse, ser convertido, sanar, salvar, aversión ¿a qué?, conversión ¿a 
quién? Ha quedado claro, bien demostrado que las ciencias humanas - junto al Evangelio- son necesarias para el estudio de la conversión. La conversión humana no es llegar a un jardín y detenerse allí, se ha dicho, sino punto de partida y proceso: la meta ya se sabe y no es de este mundo. El tiempo es factor humano decisivo; la conversión no suele ser tan instantánea como parece ni en Pablo ni en Agustín, las dos mayores conversiones, dependiente ésta de la de aquél: a Pablo se refería la voz oída por Agustín en el momento cumbre de su vida: «tolle, lege»: toma y lee.

No tuvo que ir lejos de sí mismo para encontrar lo que buscaba Agustín: «me devolvías a mí sobre mi interioridad», «me ponías a mí delante de mí mismo» (Conf. 8,16). No basta la búsqueda del extrovertido, del que nunca está en casa, alli donde Dios lo visita, nos visita y no nos encuentra.

Y es ahí mismo, en su corazón, donde Agustín oía voces amigas (pero sinceras) de lo alto: «qué sucio estás, qué desviado, cuán manchado». La conversión efectiva y afectiva están unidas entre sí.

Que ¿qué resonancia pastoral tuvo esta autobiografía una vez hecho sacerdote y obispo? Toda una interpretación del hombre y del mundo: dice haber encontrado más inquietos que inicuos en su labor pastoral, modélica. De los inquietos dice haber encontrado «enorme cantidad de hombres y mujeres», no así de los malos, de los inicuos: ¡visión esperanzada de la vida y del mundo! Por eso, visión intelectual y realismo pastoral no se oponen en el pastor.

Para ello es necesaria la gracia de Dios, pero no basta; también la fuerza de voluntad se requiere, hay que «sufrir» una cierta violencia en la carne y luz de la mente, comenzando por ésta.

\section{Fidelidad a la fe y liberalidad del pastor: ¿ecumenismo?}

"Que nadie sea obligado, mucho menos contra su voluntad a la comunión católica» es frase textual suya y pensamiento definitivo ¡y obvio! ¿Liberal? También. Prefería actuar con el diálogo que con las penas canónicas, como lo demostró una y otra vez en las reuniones con otros obispos; y nadie negará la rotunda fidelidad de Agustín a la fe de la Iglesia. Pero tenía bien claro que nadie puede ser bueno forzosa y forzadamente (invitus). Así entendió, con libertad religiosa, las expresiones de Jesús en el Evangelio de Mateo: compelle intrare, es decir, «invita encarecidamente a entrar en el Reino (evangelización) y a sertanse en la mesa del banquete del Reino (eucaristía y comunidad cristiana)». "Si te pierdes, te buscaré, quieras o no»: así leía parábolas de Jesús sobre el buen pastor, pero el acento está puesto en el sustantivo «pastor»y en el adjetivo «bueno»; y no en la coacción a la voluntad humana. 
Allá va una anécdota personal, mía, a este respecto. Gané yo un cartón de tabaco ante el reto de un sacerdote entusiasta de san Agustín que dijo a los demás sacerdotes reunidos: «doy este premio a quien sepa la definición de predestinación que da san Agustín»; para él la predestinación es la «presciencia y preparación de los bienes futuros con que certísimamente se liberan todos los que se liberan». Queda, pues, clara la libertad del hombre en comunión con la gracia actuando ésta como «delectatio victrix».

Pero siguiendo con el tema de la conversión, tema principal y específico del Congreso, saca él la conclusión de que si Dios acoge al que vuelve sobre sí y se convierte a Dios, así tiene que ser la Iglesia en sus comunidades y en sus pastores. Más aún: hay que ir a buscar la oveja perdida y atraerla (attrahere) que no es lo mismo que traerla (trahere). Aquello sí, esto no es misión de la Iglesia y de sus pastores. Por otra parte, traerla al rebaño no es convertirla: no es el pastor el que decide la conversión; «yo trato de que se despierten a la verdad, eso sí, ojalá que puesta por mí en claro y en alto para que ellos, los fieles, la busquen»; puesto que él amó tarde a Dios («sero te amavi») tuvo particular predilección por los que tarde se convertían a Dios (nunca es tarde). Se consideró a sí mismo como vocación tardía (serus advenio), pero para Dios un día es como mil años y viceversa; además Agustín siempre se atuvo a la expresión y consejo de David a su hijo Salomón: «hijo mío, si de verdad amas a Dios, lo hallarás».

\section{Purificarse-convertirse}

No es lo mismo purificarse que convertirse: este verbo, convertirse, tiene como complemento de referencia ¡a Quién!, es decir, a Dios. El intento de purificación no siempre trae consigo la entrega incondicional a Dios que es constitutivo primordial de la conversión; la purificación es fruto y resultado, expresión humana, por cierto gradual, de la gracia de la conversión a Dios.

Que ¿qué hubiera sido de san Agustín sin la conversión? No se hicieron muchas cábalas al respecto: quizás un presidente de juzgado, un gobernador de provincia, o algo similar. Pero no hablemos de futuribles: estamos aquí, convocados y reunidos, para celebrar el XVI centenario del hecho de la conversión de san Agustín -y después de un año, el próximo- se celebrará el mismo centenario de su bautismo. También esto es significativo: un adulto que consolida su conversión durante un año para bautizarse después de ese tiempo. Convertirsé a Dios, hacerse cristiano, no es sólo, pues, un esfuerzo de purificación, tarea por otra parte difícil, imposible, si no se ponen las cosas en su sitio, por su orden: la conversión a Dios en signo anterior a la aversión al pecado, como la gracia que precede el esfuerzo humano, también necesario, claro está. 


\section{$Y$ enseñar a los demás}

Aunque parezca lo contrario, lo propio de san Agustín no es tanto, no es primero, hacer doctrina, cuanto exponer la experiencia, la suya, de conversión. La aversión del pecado era difícil para él, particularmente difícil, porque amaba el aplauso, el dinero y el placer; con todo y con eso, apenas supo qué era una vida feliz hasta encontrar a Dios. Las cosas cambiaron notablemente, no del todo, cuando se hizo cristiano: la tentación sigue, pero no tiene tales imperativos ni tan exigentes: la voz de las pasiones no se ha acallado del todo, pero se oye desde lejos: prevalece la de Cristo desde cerca, subyugante.

Cabe también otra pregunta para el año que viene, año centenario de su bautismo. Esta pregunta escuece, pero habrá que estudiarla sinceramente, lealmente en Congresos como éste: ¿qué hubiera sido de Agustín si hubiera sido bautizado de niño como quería su madre? Pero no prejuzguemos cuestiones este año, centenario de su conversión; quede esa tarea, ineludible, como puente entre el centenario de la conversión y el del bautismo. Pero estamos tocando fondo, el nudo de la cuestión. ¡Cuántas ponencias, de las 155 , se han asomado tímidamente a esta cuestión!

La conversión suponía y supone un discernimiento: de las realidades de poco valor a las de mucho: una opción preferencial que toda persona adulta, responsable, se ve en la situación ineludible de hacer: no hacerla en el sentido positivo es ya hacerla en el negativo.

Así las cosas, ¿qué es primero y ante todo? El primer paso es, sin duda, acercarse a Dios, el cual creó el ser humano para ser, para ser en Dios, para subsistir en Cristo, para tener consistencia en él y hacia él. Lo demás viene por añadidura: así se va uno alejando del mal, poco a poco, día a día (a decir del Apóstol). Admitió san Agustín - cómo no- la ley de la gradualidad en la pedagogía de la conversión, como la suya: «de Juan a Pedro no va un dedo» le pareció cuando llegó a ser doctor y maestro de otras conversiones de almas - personas - a él encomendadas, si bien san Agustín nunca admitió la posibilidad de llegar a ser maestro de conversiones... ¡vana pretensión! Supuesto el acercamiento a Dios habla él a veces de conversión a sí mismo o de alejamiento del mal.

Que ¿cómo se hace una conversión de este género? No sabe explicarlo san Agustín, si bien sí sảbe explicarse en sus Confesiones: ahí están y ahí está -la conversión - al alcance de todo el mundo, como una mano tendida de Dios a toda hora y a todas las horas, hasta la última inclusive. ¡Más no! Lo avisa el Evangelio. 
Rupturas de la conversión

Sabe que la conversión lleva a la ruina de todo aquello que amamos: sea el dinero, que el aplauso que los honores «vanos». Por vanidad entiende él no lo mismo que nosotros, sino la superficialidad que es el peor mal que le puede ocurrir a uno y ojalá que no por mucho tiempo: al ser superficial no lo salva ni Dios. Pero a cambio de esa ruina tendrá felicidad y vida: a raudales. En cambio separarse de Dios es la muerte del alma y esto le impresiona.

Conjuga san Agustín los verbos en activa y en pasiva: convertirse y ser convertido: primero esto por la gracia y luego aquello. Salvemos siempre la prioridad de la gracia, pero venga muy pronto la colaboración de la voluntad, de la buena voluntad, impregnada ésta por la gracia desde dentro, muy dentro (intimis animae meae).

¿Qué antropología? Un ser humano es un ser hecho por Dios, deteriorado por el pecado, que quiere volverse a Dios; él se siente avisado, varias veces avisado, invitado a convertirse: a veces se dice que a Dios; otras, que a sí mismo: pero ya se entiende uno y otro término. No son lo mismo, pero tampoco distinto y divergente.

\section{Cuatro elementos de la conversión}

1. El primero es la $l u z$, mejor dicho, en activa: la iluminación: «ver», ¡qué cosa tan importante!; si no, cada vez caerá más y más; si tu ojo es luminoso... dice el Señor, todo tu cuerpo (tu realidad) será luminoso; tus ojos necesitan la luz, la de Dios; dar la luz es un acto creador, salvador. El mundo era un caos sin formas, sin la luz. Dijo Dios (sigue diciendo): hágase la luz, y vamos viendo, sería mejor traducción que la de «la luz se hizo».

2. Palabra de Dios y autoridad de la Iglesia. La Palabra de Dios asiste al alma, la purifica, está plena y pletórica de salvación; pero es el carisma de $\mathrm{Pe}$ dro y de la Iglesia el que me la acerca; la fuente es la Biblia, no lo olvidemos. Cristiano que no reconoce y no conoce la Biblia está perdido: ¡a qué otra palabra va a hacer caso!

3. Importancia, máxima, de la acción de la voluntad: es pasar a amar otra cosa, no es cosa, pasa de las cosas al Dios de todas ellas, aun sin éstas, puramente. Paso del bien mudable al inmutable utilizando el libre albedrío movido internamente por la gracia: a ver ¿quién invitó a quién? ¿Zaqueo a Cristo o viceversa? ¿Los novios de Caná a Cristo o viceversa? La respuesta de Agustín ya se sabe: la prioridad y precedencia de Cristo que empujó a Zaqueo a subir al árbol, que unió a los novios, luego esposos, esposos cristianos, de Caná o de donde sea.

4. La gracia divina (por aquí se empieza) que en este caso no es último 
elemento, sino primero, ya lo hemos oído. Es cosa de la misericordia de Dios. La gracia que se muestra como un acto de llamada, de insistencia, cariñosa, no, pues, a modo de filosofía: es un acto de llamada al encuentro personal con Dios, de trato íntimo con él. El clima en que se mueve el alma en todo esto es de humildad y piedad: «pietas conversionis». Una piedad que se organiza, no, pues, una veleidad. Al convertido le promete Dios el perdón de los pecados.

Entonces ¿por qué la gracia? El pecador está muerto y un muerto no puede tomar la iniciativa de vida; ésta se le regala, se nos regala: es don.

\section{Conversión y cristología}

Tienen estrecha relación entre sí la teología de la conversión con la conversión cristiana, al Dios hecho hombre; ahora bien: puesto ante Cristo, en su seguimiento, ya no hay, no puede haber rutina, sino primera conversión y segunda y continua. Como la creación continuada (¿a qué quedaríamos reducidos, a la nada, dejados de la mano de Dios?), así la conversión cristiana es continua y continuada, gradual y progresiva hasta la liberación final y definitiva, que será humana, plenamente humana y liberada: en alma y cuerpo: éste en forma distinta que la actual, frágil y pecadora. Entonces, radiante y gloriosa.

No una conversión instantánea: diez años de coloquios con Mónica, su madre; lectura de la Biblia con Ambrosio, maestro y amigo, además de obispo; tampoco aquí cabe preguntar, aunque nos sentimos tentados, qué hubiera sido sin Ambrosio y sin Mónica; y sin sus amigos, que los tuvo, y buenos: era sensible a sus amigos y a su pérdida. La sensibilidad y la amistad son lugares teológicos de conversión, sacramento de encuentro con Dios. Mucho debió san Agustín a sus amigos: quizás el prefijo y adjetivo de «san», que no fue sólo una gracia vertical, sino colateral, en su caso más que en otros, por ejemplo, que en san Pablo.

Vino a Milán Mónica, viuda, a buscar a su hijo; y lo encontró enfermo y poco menos que muerto (espiritualmente), pero iba a misa y de ahí le vino la conversión, es decir, la salvación. En cuanto a amigos, san Agustín pensaba en la vida común, compartiéndolo todo, con los bienes en común (bienes de toda índole). Le sirvieron de mucho los sermones, bien preparados, de san Ambrosio: siempre la Palabra de Dios tiene fuerza, no la suya sino la de Dios. Escuchándola y escuchándole, san Agustín se curaba de muchas enfermedades; ya sabemos cuáles: lo dice él, él las dice y confiesa abiertamente en sus libros. 


\section{El fruto de la conversión}

Antes amaba la filosofía por la filosofía; pero el nombre de Cristo no estaba allí, estaba ausente; por eso no le llenaba, no se llenaba, quedaba vacío; era ciencia, pero no sabiduría de lo bello, de lo pulcro, belleza del cuerpo (cuán distinto ahora) y del alma, la belleza espiritual: amando la paz con orden, así como no hay paz sin justicia; en cambio en la virtud hay coherencia y unidad; pero ¡ojo!, vicio y error están muy cerca del hombre, incluso virtuoso. Dios garantiza el éxito sólo al humilde y contrito, no al que se las sabe todas y se cree fuerte y sin pecado. ¡Allá él! Tendrá una vida de perversión, como la que tuvo él en Roma adonde llegó sin saberlo su madre.

Llegó incluso a autojustificarse diciendo para sí: no soy yo el que peca, sino algo (alguien) distinto de mí, dentro de mí; pero pronto se dio cuenta de que eso es echar la culpa a otro, también distinto de mí, es decir, alienación, no realismo. Creía en el amor, pero el suyo era corrompido, no puro; pero buscó a Dios intensa y metódicamente y he aquí que lo halló; y tuvo que sobrepasar infinitas contradicciones de su mente y de su carne: la verdad no era posible sin pureza y unidad interior (teniendo dentro de sí los cables sueltos, todos ellos: ideas y afectivídades...). «A los 16 años me enredé con mujeres y los padres no me pedían más que resultados de notas; me lié con una mujer y vino el consejo materno de casarme; ¿con quién?, también ahí os pasasteis»: he aquí, entre comillas, el resumen de sus quejas sobre la iniciación de sus padres, si bien siempre cariñosas, sobre todo con su madre, doblemente madre: humana y espiritualmente. ¿Que buscó la verdad en el platonismo en un tiempo? Bueno: lo llevó hacia arriba, a buscarla fuera de su cuerpo (no por ser éste malo, dirá luego a los maniqueos).

\section{Conclusiones}

1. Conversión y libro de las confesiones, el mejor libro después de la Biblia ha dicho alguien; en todo caso, lo más espléndido de la antigüedad cristiana. Es un frasco inagotable de perfume, de esencias de conversión volviendo al comienzo de este trabajo. Allá va nuestro autor hacia la conversión: el que quiera, que lo siga con el libro de las confesiones consigo.

2. Fue honesto con Dios y consigo mismo. Conversión ligada a libros y legada en libros como éste y otros, itantos! La conversión la encontró en el hombre interior: allí le esperaba Dios. Honestidad intelectual y amor a los hombres fueron dos factores importantes en su conversión.

3. ¿Esencia de la conversión? La llamada de Dios, fuente de una nueva forma de vivir: «vivir en la forma en que vivió Cristo». No hizo testamento 
san Agustín, porque no tenía de qué, pero dejó comunidades de cristianos y sacerdotes llenos de oración y pobreza.

4. Buscó el fondo común de la naturaleza humana, no el vicio que la desnaturaliza y aleja. De la conversión de san Agustín viene todo en cascada imparable hasta nuestros días, útil también, sobre todo, para jóvenes de hoy, para personas de toda edad y condición.

José Luis LARRABE 